Preliminary Evaluations of Polymer-based Lithium Battery Electrolytes under development for the Polymer Electroyte Rechargeable Systems Program

\author{
Willam R. Bennett \\ QSS Corporation \\ and \\ Michelle A. Manzo \\ NASA Glenn Research Center
}

In fiscal year 2000, NASA, established a program to develop the next generation, lithiumbased, polymer electrolyte batteries for aerospace applications. The goal of this program, known as PERS, Polymer Rechargeable Energy Systems, is to develop a spacequalified, advanced battery system embodying polymer electrolyte (SPE) and lithiumbased electrode technologies and to establish world-class domestic manufacturing capabilities for advanced batteries with improved performance characteristics that address NASA's future aerospace battery requirements.

A NASA Research Announcement (NRA) was released in FYOO to solicit efforts to address the development of the polymer electrolytes, cathodes and anodes for PERS batteries. Development of a polymer with Room Temperature conductivity in the range of $10^{-3} \mathrm{~S} / \mathrm{cm}$ has been identified as the enabling technology breakthrough required for this battery system. There are currently 5 contracts and 4 grants in place that address various aspects of component level development required for the PERS batteries. In addition to the above contracts and grants, research and development activities have been supported at JPL, AFRL and at GRC.

A component screening facility has been established at GRC and test procedures have been developed to evaluate the materials developed via the supported R\&D efforts. These procedures were implemented to provide "standardized" measurements of electrolyte characteristics for next-generation, lithium batteries. Strengths and weaknesses of the measurement methods are discussed. Results contrasting commercial liquid electrolyte, poly(ethylene oxide) and experimental polymer electrolytes are also presented.

This is a preprint or reprint of a paper intended for presentation at a conference. Because changes may be made before formal publication, this is made available with the understanding that it will not be cited or reproduced without the permission of the author. 


\section{PRELIMINARY EVALUATIONS OF POLYMER-BASED LITHIUM BATTERY ELECTROLYTES UNDER DEVELOPMENT FOR THE POLYMER ENERGY RECHARGEABLE SYSTEMS PROGRAM}

\author{
William R. Bennett \\ QSS Group, Inc. \\ 21000 Brookpark Road, MS 309-1 \\ Cleveland, $\mathrm{OH} 44135$ \\ Michelle A. Manzo \\ NASA John H. Glenn Research Center \\ 21000 Brookpark Road, MS 309-1 \\ Cleveland, $\mathrm{OH} 44135$
}

\begin{abstract}
A component screening facility has been established at The NASA Glenn Research Center (GRC) to evaluate candidate materials for next generation, lithium-based, polymer electrolyte batteries for aerospace applications. Procedures have been implemented to provide "standardized" measurements of critical electrolyte properties. These include ionic conductivity, electronic resistivity, electrochemical stability window, cation transference number, salt diffusion coefficient and lithium plating efficiency. Preliminary results for poly(ethylene oxide)-based polymer electrolyte and commercial liquid electrolyte are presented.
\end{abstract}

\section{INTRODUCTION}

In fiscal year 2000, NASA, established a program to develop the next generation, lithium-based, polymer electrolyte batteries for aerospace applications. The goal of this program, known as Polymer Energy Rechargeable Systems (PERS), is to develop a space-qualified, advanced battery system embodying solid polymer electrolyte (SPE) and lithium-based electrode technologies and to establish world-class domestic manufacturing capabilities for advanced batteries with improved performance characteristics that address NASA's future aerospace battery requirements.

A NASA Research Announcement (NRA) was released in FYOO to solicit efforts to address the development of the polymer electrolytes, cathodes and anodes for PERS batteries. The development of a polymer electrolyte with room temperature conductivity in the range of $10^{-3} \mathrm{~S} / \mathrm{cm}$ has been identified as the enabling technology breakthrough required for this battery system. There are currently 5 contracts and 4 grants in place that address various aspects of component level development required for the PERS batteries. In addition to the above contracts and grants, research and development activities have been supported at JPL, AFRL and at GRC.

Electrochemical screening of candidate materials is being done at GRC. Goals for the critical parameters of PERS SPE materials are listed below.

1) High ionic conductivity $\left(\sim 10^{-3} \mathrm{~S} / \mathrm{cm}\right)$

2) Low Electronic Conductivity $\left(<10^{-12} \mathrm{~S} / \mathrm{cm}\right)$

3) Electrochemical Stability Window 0 to $>4 \mathrm{~V}$

4) Favorable $\mathrm{Li}^{+}$transport properties

a) $\mathrm{Li}^{+}$transference number approaching 1

b) High salt diffusion coefficient

5) Favorable Interfacial Properties

a) Low interfacial impedance

b) Stable transport properties

6) Thermal stability

7) Mechanical toughness

This paper describes specific test methods that have been selected and presents typical results. Advantages and shortcomings of the test methods are presented.

\section{EXPERIMENTAL}

Ionic Conductivity

Conductivity is determined by electrochemical impedance spectroscopy (EIS) methods, using a Solartron 1250 frequency response analyzer coupled to a Solartron 1286 electrochemical interface. The operation of these instruments is automated using Scribner and Associates' Zplot ${ }$ software for Windows. Impedance is measured using a $10 \mathrm{mV}$ signal $(55 \mathrm{kHz}$ to $0.1 \mathrm{~Hz}$ ) with the cell held at 0 Volts vs. open circuit. Overviews of the method appear in the literature. ${ }^{2,3}$

The standard fixture uses $25 \mathrm{~mm}$ diameter, AISI 304 stainless steel blocking electrodes, mounted in rigid, electrically insulating plates. The electrodes are lapped flat with the inside face of the plate, and polished with 600 grit emery cloth. Inter-electrode spacing is established using polyester shims, selected to assure slight compression (1 to 2 mils) of the SPE sample material. Usually, the shim is shaped as a mask with a $5 / 8$ inch diameter hole which captures the test specimen at the center of the cell. Parts are illustrated in Figure 1. 


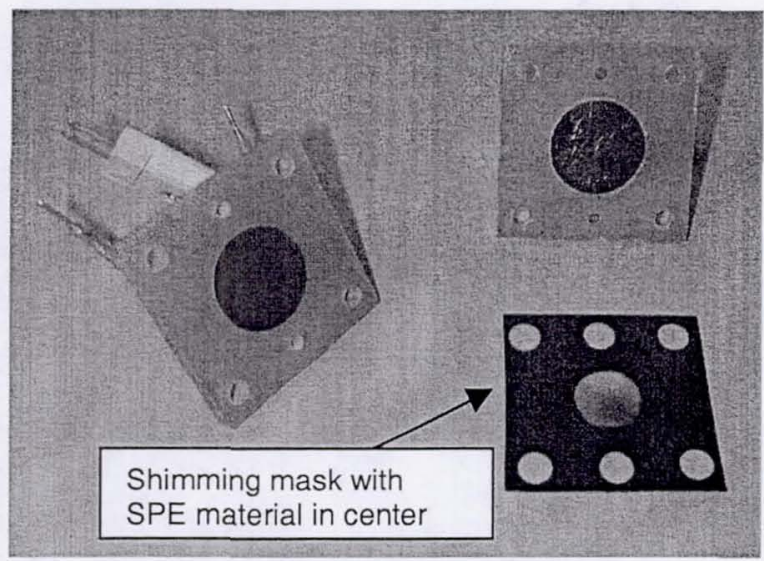

Figure 1: Conductivity Cell Parts

This fixture uses a four-wire connection up to the back of each stainless steel electrode. Current passes through the working electrode (WE) and counter electrode (CE) connections. Reference electrode connections (RE1 and RE2) monitor voltage (see Figure 2). A thermocouple is bonded to the backside of one of the steel electrodes to provide the most intimate possible measure of sample temperature.

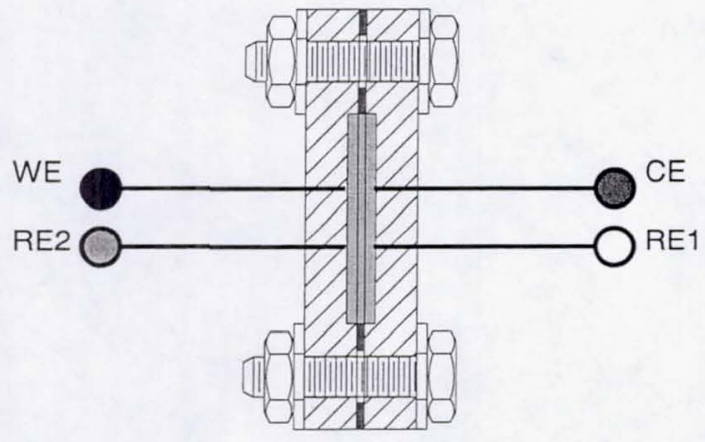

Figure 2: Four-Wire Potentiostat Connections

Material handling and cell assembly is performed inside an inert atmosphere glovebox to minimize the absorption of water (humidity $\leq 1 \mathrm{ppm}$ ). After assembly, the fixtures are sealed in modified Nalgene ${ }^{T M}$ jars before being transferred out of the glovebox atmosphere for testing. Conductivity measurements are completed over a temperature range of $0^{\circ} \mathrm{C}$ to $80^{\circ} \mathrm{C}$. Temperature is allowed to stabilize at $\pm 0.1^{\circ} \mathrm{C}$ before test.

Material thickness, $L$, and area, $A$, are controlled by the fixture and electrochemical impedance data provides a measure of sample bulk-resistance, $R_{b}$. Ionic conductivity, $\kappa$, iscalculated by equation (1).

$$
\kappa=\frac{L}{A R_{b}}
$$

\section{Electronic d.c. Conductivity}

Electronic d.c. conductivity is measured using the conductivity fixture described above. For this test, a constant d.c. potential $(500 \mathrm{mV})$ is applied and the current is allowed to reach steady state. Resistance, $R_{\text {d.c. }}$, is calculated by Ohm's law using the steady state current and potential.

\section{Electrochemical Stability Window}

Resistance to oxidation/reduction is measured by cyclic voltammetry using a commercially available, platinum electrode (BioAnalytical Systems, 1.6 mm dia., P/N MF-2013).

Free-standing SPE films are mounted in a $\mathrm{Pt} / \mathrm{SPE} / \mathrm{Li}$ configuration using hardware that was prepared in house. A $1 / 2$ inch diameter lithium disc, mounted to a nickel electrode holder, serves as both counter electrode and pseudo-reference. This fixture can be set up for constant gap or constant pressure using a precision spring. Parts are illustrated in Figure 3.

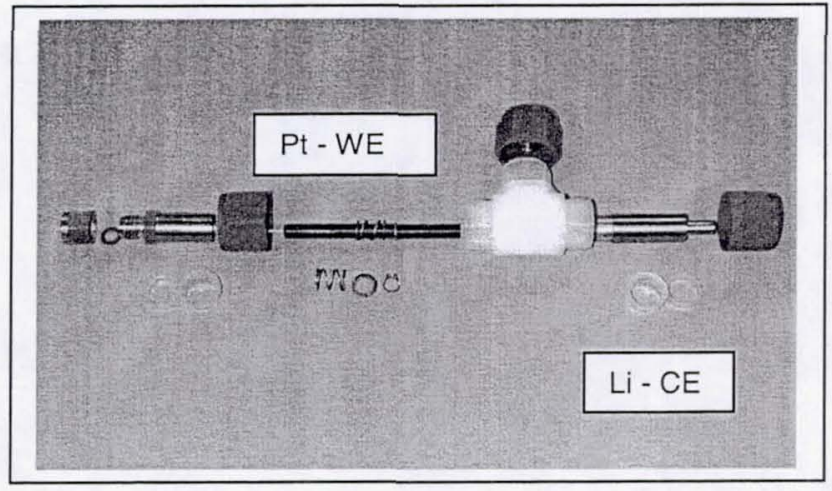

Figure 3: Tee-Cell with Pt Working Electrode

Because many of the SPE films under evaluation are quite thin (as little as $25 \mu \mathrm{m}$ ), it would be difficult to include a separate reference electrode within the sample. It is believed that the affects of polarization at the counter electrode are small and that it can be used as a pseudo reference.

Measurements are completed using a Solartron 1286 electrochemical interface. Operation is automated using Scribner and Associates' 
Corrware $\AA$. Cell potential is cycled at a uniform rate from $1 \mathrm{~V}$ to $>4 \mathrm{~V}$ at a scan rate of $10 \mathrm{mV} / \mathrm{sec}$.

\section{Lithium Transport Properties}

Cation transference number of polymer electrolytes is being estimated using steady state current measurements with correction for interfacial impedance effects. This method is described in detail by Bruce and Vincent and is sometimes referred to as the d.c. method. ${ }^{4,5}$ This technique is based on low polarization voltages and assumes no supporting electrolyte and no ionic associated species. Concentrated polymer electrolytes can be expected to have associated ions at the concentrations encountered in practical battery systems. Therefore, this measurement may not provide a true measure for the cation transference number and misapplication of the technique has received some criticism in the literature. ${ }^{6}$ Nonetheless, the author believes that the technique has value as a screening tool and represents a best compromise for preliminary evaluations of candidate SPE materials.

This method uses a symmetric, Li/SPE/Li, cell. Here, SPE samples are sandwiched between 1 $\mathrm{cm}^{2}$ lithium electrodes with enough spring force to assure uniform face contact.

\section{Figure 3: Tee-Cell with Symmetric Li Electrodes}

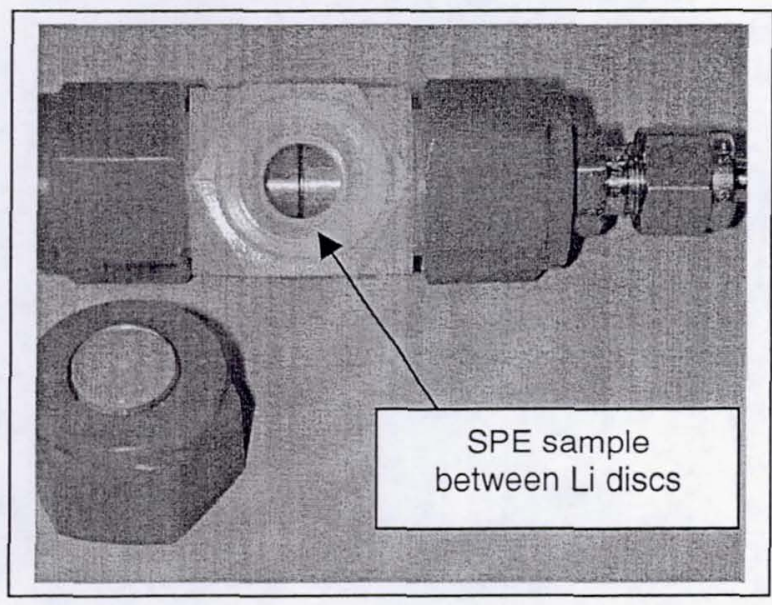

A constant potential difference $(10 \mathrm{mV})$ is applied to the cell and the current response is recorded with time, until a steady state value is observed. Transference number is calculated from:

$$
t_{+}^{\text {d.c.method }}=\frac{I^{S}\left(\Delta V-I^{0} R^{0}\right)}{I^{0}\left(\Delta V-I^{S} R^{S}\right)}
$$

In equation (2), $S$ and $P$ are the steady state and initial current respectively, $\Delta V$ is the applied potential $(10 \mathrm{mV})$ and $R^{S}$ and $R^{0}$ are steady state and initial interfacial impedance, respectively. Measurements are automated using the Solartron and Scribner equipment described above.

Nishimoto et al. describe an alternative calculation for an "apparent" transference number. ${ }^{7}$

$$
t_{+}^{\text {apparent }}=\frac{R_{b}}{\Delta V / I^{S}-R^{\text {int }}}
$$

This alternative equation applies when the interfacial impedance does not change over time, so that $R^{0} \approx R^{S}=R^{\text {int }}$. The quantity $R_{b}$ in equation (3) represents the bulk resistance, which is also obtained during the impedance experiment.

\section{Salt Diffusion Coefficient}

Salt diffusion coefficient is calculated using a restricted diffusion method. ${ }^{8}$ In this procedure, a $\mathrm{Li} / \mathrm{SPE} / \mathrm{Li}$ cell is polarized at a constant current then allowed to relax at open-circuit. After a period of time, the open-circuit voltage is governed by the relaxation of concentration gradients in the sample. This diffusion limited process is described by Equation (4).

$$
\ln \Delta \phi=-\frac{\pi^{2} D_{S}}{L^{2}} t+A
$$

where:

$\Delta \phi$ is the cell potential

$D_{s}$ is the salt diffusion coefficient

$t$ is time

$L$ is the SPE sample thickness

$A$ is a constant.

The slope, $\pi^{2} D_{s} / L^{2}$, is determined by linear regression of $\ln (\Delta \phi)$ versus time. For screening purposes, this experiment has been performed following transference number measurements.

\section{Electrochemical Stability}

Charge/discharge behavior of SPE materials is being monitored using symmetric Li/SPE/Li, 2325 coin cells. Cell temperature is controlled at $\pm 1^{\circ} \mathrm{C}$. Cells are cycled galvanostatically using an Arbin BT2043 instrument and electrochemical impedance is scanned before and after cycling.

This testing provides data that can be correlated with the transport properties of the SPE samples 
and provides a measure of the stability of the electrochemical interface that is formed on lithium.

Thermal Stability

Thermal characterization is being conducted using TA Instruments' DSC 2910 and TGA Model 2050. Characterizations quantify thermal decomposition, melting and phase transition.

\section{Material Properties}

Preliminary measures of mechanical strength are based on mandrel bend testing (ASTM D 522) and Durometer hardness testing (ASTM D 2240). Results provide comparative measures of SPE strength at room temperature. These measurements do not provide numerical values for the physical properties of SPE materials.

Moisture content of critical materials is measured using a Mitsubishi model CA/VA-100 moisture analyzer.

\section{SPE Preparation}

Polymer electrolytes based on Poly(ethylene oxide) $\quad P(E O)$ and lithium bis(trifluoromethanesulfonyl)imide salt (LiTFSI) are being used as "standards" and for verification purposes.

$\mathrm{P}(\mathrm{EO})$ (Aldrich, 6E5 Mv) and acetonitrile (Baker $\otimes$ hplc grade) were used as received. LiTFSI salt (3M HQ-115) was dried for 4 hours under vacuum at $160^{\circ} \mathrm{C}$. $P(E O)$ was pre-dissolved as a $12.3 \mathrm{w} / \mathrm{w}$ solution in acetonitrile before addition of $23.4 \mathrm{w} / \mathrm{w}$ LiTFSI-acetonitrile solution. Quantities were established to provide a 16:1 ether-oxygen:lithium ratio after evaporation of the acetonitrile solvent. This concentration is equivalent to $28.9 \mathrm{w} / \mathrm{w}$ LiTFSI in the solid electrolyte.

$P(E O)_{16}$ LiTFSI films were routinely prepared by casting the above solution in Teflon ${ }^{\mathrm{TM}}$ Petri dishes and allowing the solvent to evaporate overnight. Casting and solvent evaporation steps were conducted in the dry room atmosphere $\left(<-35{ }^{\circ} \mathrm{C}\right.$ dew point). Cured SPE films were dried overnight under vacuum at $45^{\circ} \mathrm{C}$ and stored in a desiccator before use. This process produced rubbery, freestanding films with a strong self-adherent character. Dry film density at room temperature was $1.26 \mathrm{~g} / \mathrm{cm}^{3}$, giving a salt concentration of 1.27 mole LiTFSI/liter.

\section{RESULTS AND DISCUSSION}

\section{Conductivity}

Electrochemical impedance data for $\mathrm{P}(\mathrm{EO}){ }_{16} \mathrm{LiTFSI}$ at $25^{\circ} \mathrm{C}$ appears in Figure 4 . These results are typical of the spectra reported in the literature. Generally, the spectrum is dominated by an angled, low-frequency spike. Depending on material properties, a semicircular, high frequency arc may also be visible.

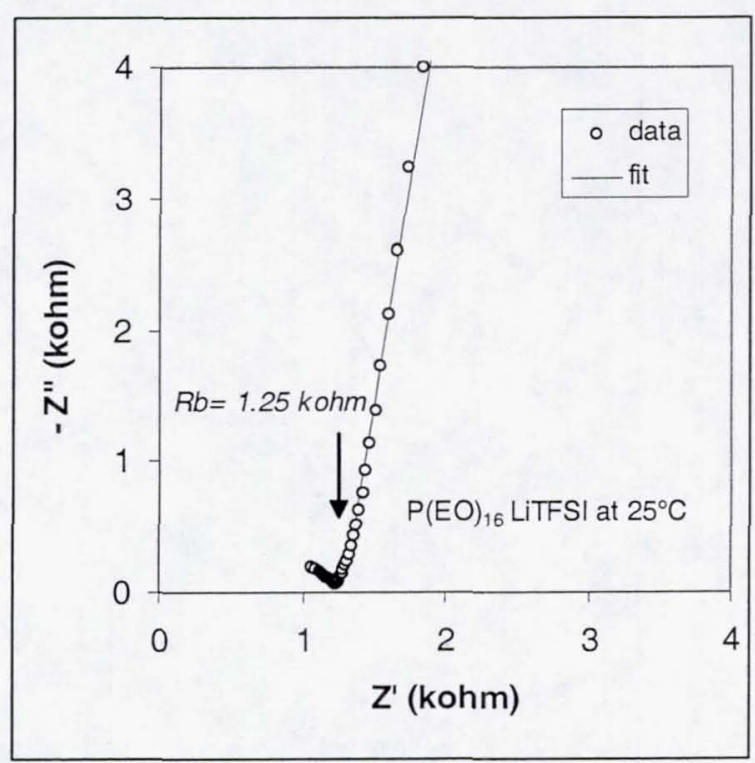

Figure 4: Impedance with Blocking Electrodes

The material bulk resistance, $R_{b}$, is estimated from the Z'-axis intercept of the low-frequency spike. As illustrated in Figure 4,

$$
\text { by intercept: } R_{b}=1.25 \mathrm{kohm}
$$

This is the quantity used in equation (1) to calculate ionic conductivity.

The spectrum in Figure 4 can also be interpreted in terms of the equivalent circuit model shown in Figure 5.

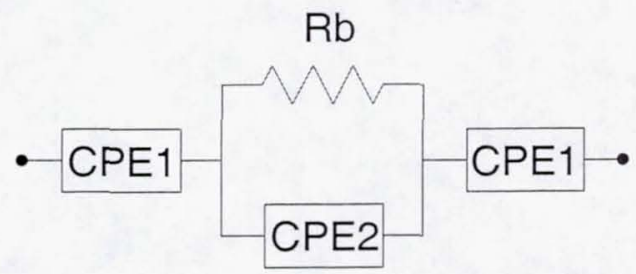

Figure 5: Conductivity Equivalent Circuit 
In this model, constant phase elements (CPE1 and CPE2) are associated with the interfacial and bulk capacitance of the material, respectively. In our experience, the SPE materials tested have typically produced impedance spectra like the one shown in Figure 4. The sloped, low-frequency spike and high-frequency arc are best described using CPE's in place of pure capacitors. Discussions of this model appear in the literature. ${ }^{2}$

Under some circumstances, the impedance spectrum will not include a pronounced linear spike that is suitable for defining a Z'-intercept. In those instances, the model in Figure 5 is used in conjunction with parameter fitting software to extract the bulk resistance. For the impedance data in Figure 4:

$$
\text { by parameter fitting, } R b=1.29 \text { kohm. }
$$

In the author's experience, the difference between these fitting methods is roughly 2 to $5 \%$.

Accuracy of conductivity measurements was estimated from the combined tolerances of sample thickness, sample area and bulk resistance. For thin specimens $(<250 \mu \mathrm{m})$ the estimated uncertainty for measured conductivity is $-20 \%$.

One advantage of using impedance spectroscopy for conductivity measurements is that the specific frequency that corresponds to $R_{b}$ can be identified. This becomes important when evaluating materials with widely different properties or for the same material over a broad range of temperature. Under some circumstances, the critical frequency that corresponds to $R_{b}$ can vary by more than an order-of magnitude. The Bode plot in Figure 6 illustat es this frequency dependence.

Here, $R_{b}$ is roughly equal to the magnitude, $|Z|$, measured at the frequency corresponding to the minimum phase angle. For this sample, the corresponding frequency changes by about an order-of-magnitude every $20^{\circ} \mathrm{C}$ (see Figure 6).

Given $R_{b}=1250$ ohms, the conductivity for this sample is calculated to be $7.7 \mathrm{E}-6 \mathrm{~S} / \mathrm{cm}$ at $25^{\circ} \mathrm{C}$. Conductivity is routinely measured over a range of temperatures. Results for $\mathrm{P}(\mathrm{EO})_{16} \mathrm{LiTFSI}$ are summarized in Figure 7.
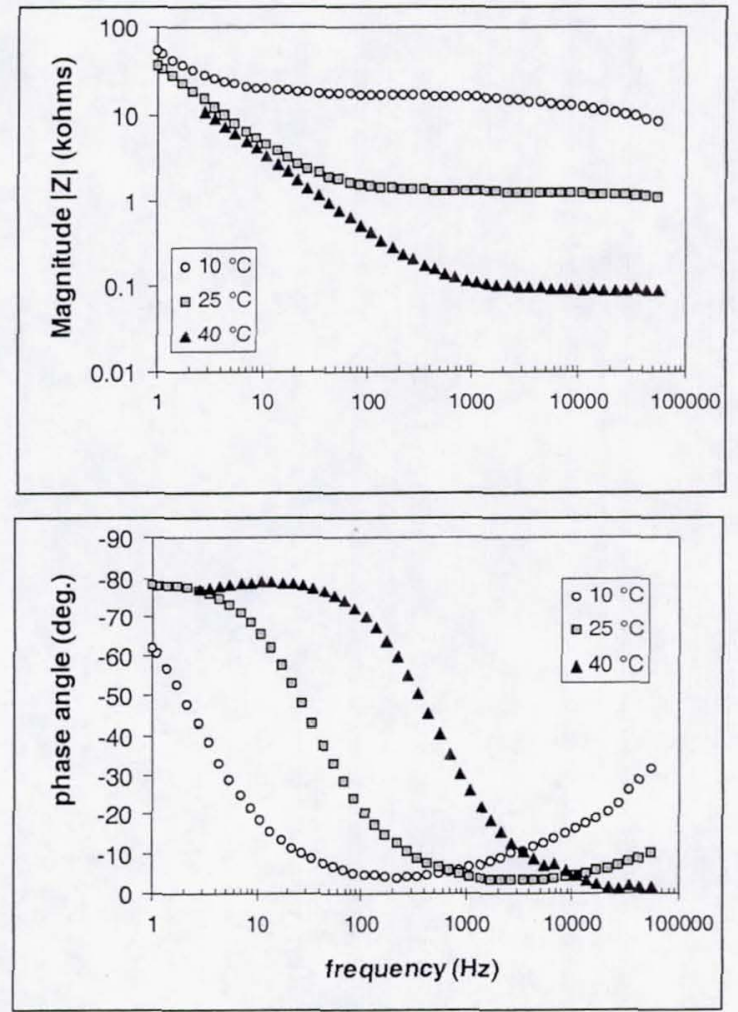

Figure 6: Impedance Data for $\mathrm{P}(\mathrm{EO})_{16}$ LiTFSI

Error bars in Figure 7 illustrate the $\pm 20 \%$ uncertainty calculated above. Over this temperature range, conductivity changes by orders-of-magnitude.

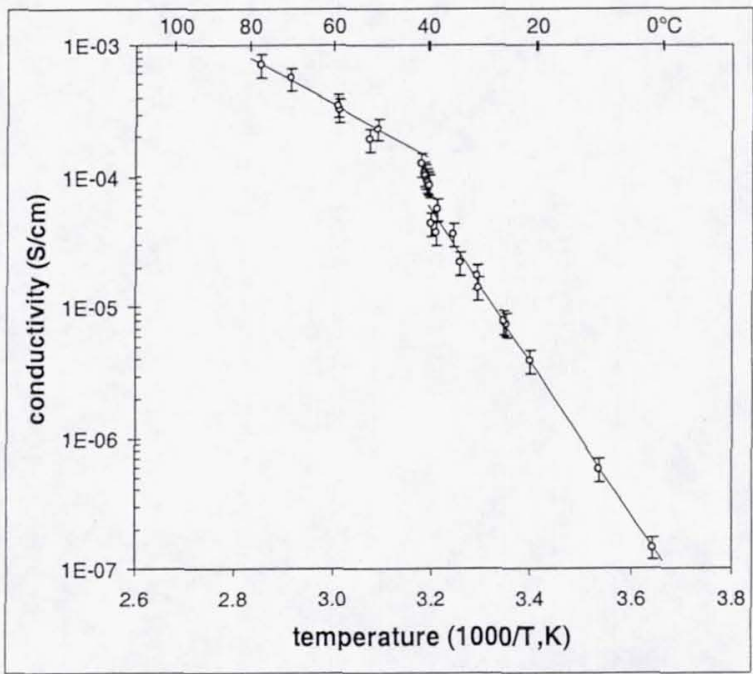

Figure 7: Conductivity of $\mathrm{P}(\mathrm{EO}){ }_{16}$ LiTFSI 
This sample shows a transition in the conductivitytemperature relationship at approximately $40^{\circ} \mathrm{C}$ (see Figure 7). The transition corresponds to a broad phase change that is observed in the DSC for this material (data at $10^{\circ} \mathrm{C} / \mathrm{min}$.).

Figure 8: $\mathrm{P}(\mathrm{EO})_{16}$ LiTFSI DSC Results

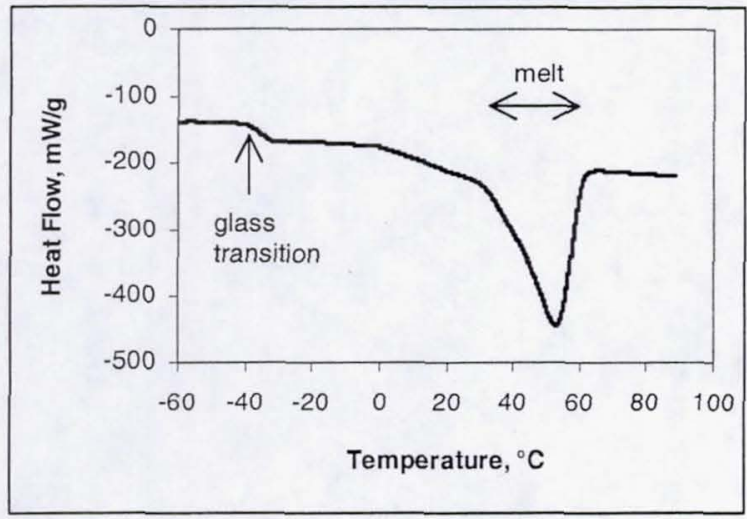

This $P(E O)$-based electrolyte does not achieve a practical level of conductivity at temperatures less than $80^{\circ} \mathrm{C}$. Of course, at those temperatures there is a liquid phase present and the material is no longer a true solid polymer electrolyte.

For comparison, liquid electrolytes used in lithiumion cells (e.g. $1 \underline{M}$ LiPF $_{6}$ in 1:1 EC:DMC) have room temperature conductivity of $\sim 2 \times 10^{-3} \mathrm{~S} / \mathrm{cm}$. Note that this includes the effects of tortuosity associated with the porous, polypropylene separator material.

Electronic d.c. conductivity was measured for this material at $\sim 60^{\circ} \mathrm{C}$ and $500 \mathrm{mV}$. After approximately one hour, a steady-state current of $0.146 \mu \mathrm{A}$ was established. By Ohm's law,

$R_{\text {d.c. }}=0.5 \mathrm{~V} / 0.146 \mathrm{E}-7 \mathrm{~A}=3.42 \mathrm{M} \Omega$

The d.c. conductivity is calculated using known sample dimensions by equation (1). Here, the d.c. conductivity is $4.3 \mathrm{E}-9 \mathrm{~S} / \mathrm{cm}$. Using this method with liquid electrolyte in a polypropylene separator (Celgard® 3501 saturated with $1 \underline{\mathrm{M}} \mathrm{LiPF}_{6}$ in 1:1 EC:DMC), the d.c. conductivity was observed to be $3.9 \mathrm{E}-10 \mathrm{~S} / \mathrm{cm}$.

\section{Cation Transference Number}

Raw data and calculations for the lithium transference number are illustrated below for $\mathrm{P}(\mathrm{EO})_{16} \mathrm{LiTFSI}$ at $60^{\circ} \mathrm{C}$.
Initial and steady-state current are determined at a cell potential of $10 \mathrm{mV}$ (see Figure 9).

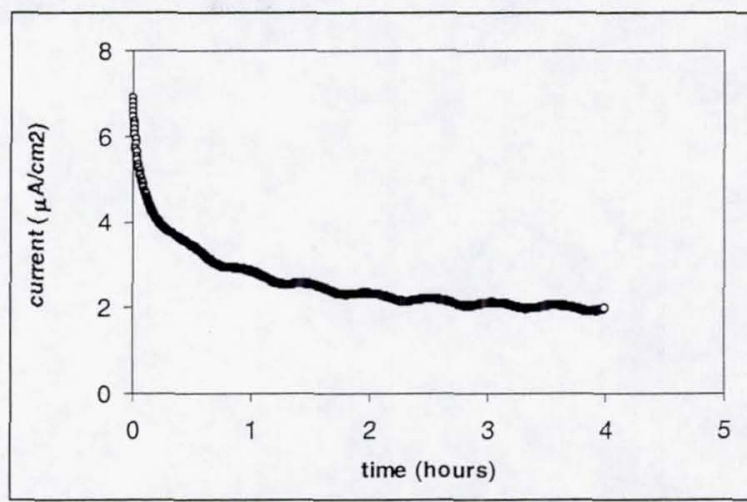

Figure 9: Steady-State Current with non-Blocking. Lithium Electrodes

Here, current approaches steady state after about 4 hours of polarization. Note: the ripple in Figure 9 is due to temperature fluctuations. Improved equipment has been set-up to address this issue.

Initial and steady-state interfacial impedance $\left(R^{0}\right.$ and $R^{s}$ respectively) are determined from EIS data. Interfacial impedance was observed to increase slightly following the 4-hour polarization experiment (see Figure 10).

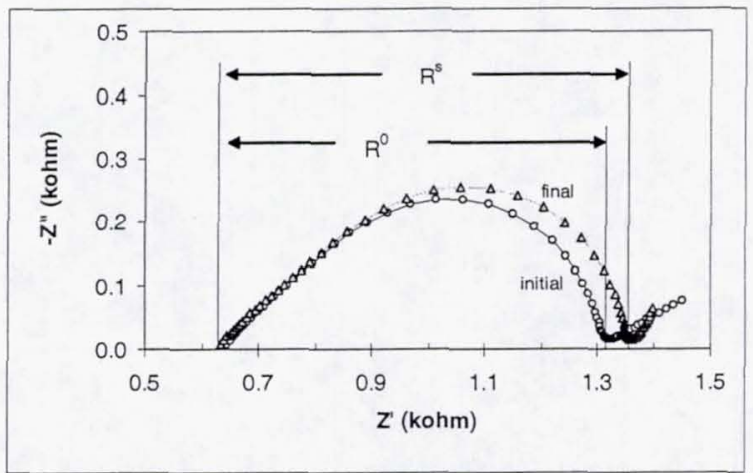

Figure 10: Electrochemical Impedance

The spectra in Figure 10 shows features that can be interpreted in terms of film resistance, charge transfer resistance and diffusion limitations. The high-frequency intercept (628 ohms) corresponds to the bulk resistance of the electrolyte and provides an alternative measure of ionic conductivity. The low-frequency Warburg impedance (which begins at $\sim 1 \mathrm{~Hz}$ in this data) was neglected in assigning values to $R^{0}$ and $R^{s}$.

Calculations for $t^{+}$are summarized in Table I. 
Table I: Transference number calculations:

\begin{tabular}{lrl}
\hline$\Delta V$ & 10 & $\mathrm{mV}$ \\
$P$ & 6.68 & $\mu \mathrm{A}$ \\
$s$ & 1.89 & $\mu \mathrm{A}$ \\
$R^{0}$ & 685 & ohms \\
$R^{S}$ & 727 & ohms \\
\hline$t+$ (dc method) & 0.18 & \\
$t+$ (apparent) & 0.14 & \\
\hline
\end{tabular}

In this case, both calculation methods produce similar values for transference number. Results are similar to values reported in the literature for PEO-LiTFSI electrolyte.,

Efforts to perform like measurements with liquid electrolytes were confounded by the formation of mossy lithium deposits and concomitant short circuiting. Preliminary results for Celgard $(3501$, saturated with $1 \underline{\mathrm{M}} \mathrm{LiPF}_{6}$ in 1:1 EC:DMC show transference numbers that range from 0.15 to 0.32 at room temperature. This result is very similar to the results achieved for $\mathrm{P}(\mathrm{EO}){ }_{16} \mathrm{LiTFSI}$ at $60^{\circ} \mathrm{C}$.

The advantage of this technique is that a value can be obtained form a single experiment. A disadvantage is a moderately long time for establishment of the steady-state current, which can take over 12 hours depending on the sample. Before a repeat measurement can be made, the cell should be allowed to equilibrate at open-circuit which would require a like amount of time.

Possibly, the most significant disadvantage is that some of the assumptions on which this method is based do not apply to most concentrated polymer electrolytes. Therefore, results may not compare with values measured by other techniques. More rigorous techniques are described in the literature; however, these methods are based on multiple experiments and are presumed to be more time consuming than the d.c. method. ${ }^{9-11}$ At this time, it is believed that the d.c. method is suitable for inhouse comparisons between candidate materials. More rigorous measures need to be evaluated for the best candidates at a later time.

\section{Diffusion Coefficient}

The salt diffusion coefficient is measured by voltage relaxation at open-circuit. In preliminary work, this has been done after long polarization times, following the transference number measurement discussed above. Example data for $\mathrm{P}(\mathrm{EO})_{16} \mathrm{LiTFSI}$ at $60^{\circ} \mathrm{C}$ is plotted in Figure 11.

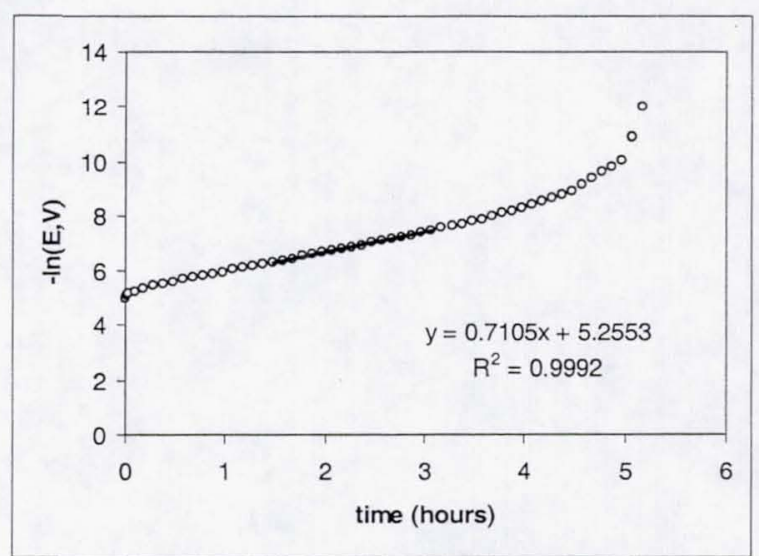

\section{Figure 11: Restricted Diffusion Data}

In this experiment, a linear region appears after about 1 hour. The slope (units adjusted to seconds) is $1.97 \mathrm{E}-4 \mathrm{~s}^{-1}$. Given sample thickness, $L$, equal to $0.096 \mathrm{~cm}$; equation (4) indicates a salt diffusion coefficient of $1.9 \mathrm{E}-7 \mathrm{~cm}^{2} / \mathrm{s}$.

As noted above, this measurement was made after the steady state current experiment. As a result, the salt concentration gradient would have extended well into the bulk of the SPE layer. It may be more correct to complete this measurement after shorter polarization intervals. ${ }^{8}$

A rough check of the measured values for diffusion coefficient and transference number can be completed by comparing limiting current measurements with projections. Limiting current can be estimated by equation $(5)^{12}$.

$$
I_{\text {Lim }}=\frac{F D_{S}}{\left(1-t_{+}\right)} \frac{\Delta c}{\Delta L}
$$

Here, $F$ is Faraday's constant, $\Delta c$ is equal to the bulk salt concentration and $\Delta L$ is the distance between the electrodes. Using the values above, the limiting current for a $58 \mu \mathrm{m}$ thick $P(E O){ }_{16} \mathrm{LiTFSI}$ film is estimated to be $0.49 \mathrm{~mA} / \mathrm{cm}^{2}$ at $60^{\circ} \mathrm{C}$. Limiting current for this material was measured in a symmetric cell by scanning current at $5 \mu \mathrm{A} / \mathrm{sec}$. Using a $5 \mathrm{~V}$ cutoff, the observed limiting current at $60^{\circ} \mathrm{C}$ was $0.43 \mathrm{~mA} / \mathrm{cm}^{2}$. This result compares favorably with the calculated value above and provides a rough order-ofmagnitude check on the measured transport properties.

In addition to limiting current, galvanostatic cycling of SPE materials in symmetric cells provides a 
measure of the interfacial stability in the presence of lithium. This work is in its early stages and results are not presented in this summary. It is planned to use coin cell hardware to replace Teecell hardware in future measurements that use symmetric Li/SPE/Li configurations.

\section{Potential Stability Window}

Potential stability window for $\mathrm{P}(\mathrm{EO}){ }_{16} \mathrm{~L}$ LiTFSI was measured at $60^{\circ} \mathrm{C}$. This material shows evidence of oxidative decomposition between 4 and $4.5 \mathrm{~V}$. Stability limit increased slightly with cycling (see Figure 12).

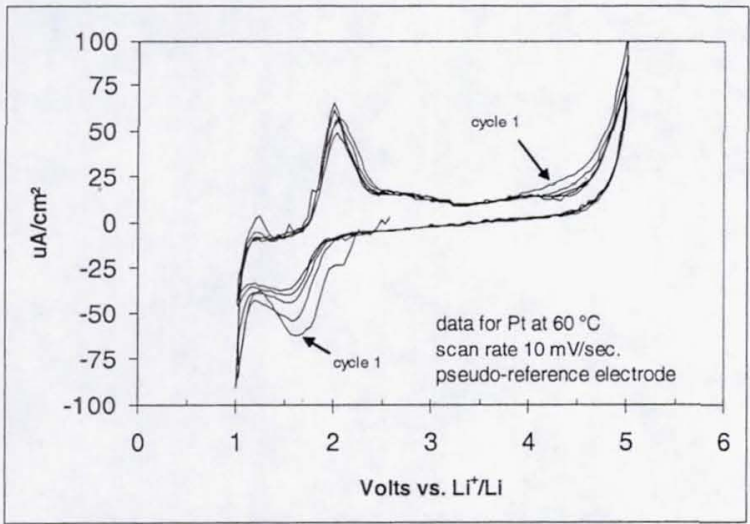

Figure 12: Potential Stability Window

Similar anodic decomposition limits have been reported for LiTFSI in plasticized $\mathrm{P}(\mathrm{EO})$-based electrolyte ${ }^{13}$. Cathodic decomposition is evident for this sample at 1 Volt. Also, there appears to be a reversible reaction associated with peaks at $\sim 1.5$ (cathodic scan) and 2 Volts (anodic scan). The reactions are not understood by the author at this time.

In earlier work with liquid-solvent-based electrolytes, no significant difference in stability limit was evident for different working electrodes (Pt, glassy-carbon and nickel were examined). Therefore, platinum was selected as a working electrode material for standard screening purposes. Recently, investigators have reported significantly lower stability limits for PEO-based electrolytes when hi-surface area, non-blocking electrode materials are used ${ }^{14}$. In the future, this standard test will be expanded to examine sensitivity to working-electrode material.

In addition to electrochemical screening, limited mechanical testing has been done to evaluate resistance to penetration and crack resistance. These relative measures are being pursued to compare materials and do not quantify mechanical strength. No data is presented in this summary.

\section{CONCLUSIONS}

The test procedures selected for screening PERS materials provide a balanced measure of relative performance. Preliminary evaluations with "standard", PEO-based electrolyte have given results that are close to those documented in the literature. In particular, measures of ionic conductivity, diffusion coefficient and potential stability window are relatively straightforward and uncontroversial. Preliminary values for diffusion coefficient have been based on open circuit voltage relaxation after long polarization times. Brief polarization times will be examined in future work to identify differences and refine the in-house procedure.

Transference number is difficult to measure for solid polymer electrolytes and the method selected for this work represents a best compromise for rapid screening of limited samples. It is expected that this tool is sufficient, at least, to distinguish large differences in transference number. More rigorous methods exist and these will be explored in the future. Cycling data collected with symmetric cells provides results that can be used to help verify transport property measurements.

The $\mathrm{P}(\mathrm{EO})_{16} \mathrm{LiTFSI}$ electrolyte evaluated in this summary was selected as a medium for selecting and developing test procedures. This material does not satisfy the stated PERS goals for a room temperature, polymer electrolyte.

\section{References}

[1] R. S. Baldwin et al., NASA/TM-2001-210217

[2] Electrochimica Acta, 46 (2001) 1829-1836

[3] J. of The Electrochemical Soc., 147 (9) 3219$3225(2000)$

[4] J. of Electroanalytical Chem., 225 (1987) 1-17

[5] Polymer, Vol. 28, December (1987)

[6] Electrochimica Acta, 47 (2001) 577-587

[7] Electrochimica Acta, 43 (2001) 1177-1184

[8] J. of Power Sources, 89 (2000) 149-155

[9] J. Electrochem. Soc., Vol. 142, No. 6, June 1995, pp. 1859-1868

[10] Electrochimica Acta, 43 (2001) 1387-1393

[11] J. of The Electrochemical Soc., 146 (6) 20242028 (1999)

[12] Newman, Electrochemical Systems, PrenticeHall, 1973

[13] Solid State Ionics 149 (2002) 29-37 
[14]I. W. Cheung et al., Electrochimica Acta (2003) 1-8, Article In Press 